\title{
Increased proximity of vessels reduces feeding opportunities of blue whales in the St. Lawrence Estuary, Canada
}

\author{
Véronique Lesage $^{1, *}$, Abdelghani Omrane ${ }^{1,2}$, Thomas Doniol-Valcroze $^{1}$, \\ Arnaud Mosnier ${ }^{1}$
}

\author{
${ }^{1}$ Maurice Lamontagne Institute, Fisheries and Oceans Canada, Mont-Joli, Quebec G5H 3Z4, Canada \\ ${ }^{2}$ Institut des sciences de la mer de Rimouski, Université du Québec à Rimouski, Rimouski, Québec G5L 3A1, Canada
}

\begin{abstract}
Blue whales Balaenoptera musculus occur seasonally in the St. Lawrence Estuary, Canada, where they spend most of their time foraging. Their recurrent presence has stimulated the development of a large whale-watching industry. Here, we examine the effect of vessel distance on blue whale foraging behaviour by measuring changes in surface and diving patterns. Vessels were within $2000 \mathrm{~m}$ of blue whales during $70 \%$ of 33 follows, and $59 \%$ of total observation time. At vessel distances $\leq 400 \mathrm{~m}$, surface and dive times were on average 49 and $36 \%$ shorter, respectively, and the number of breaths taken by the whales was reduced by $51 \%$ compared to control observations without vessel presence within $2000 \mathrm{~m}$ of whales. The consequent reduction in foraging time was likely greater than $36 \%$, given that transit time is incompressible and foraging depth is dictated by where krill densities are located. We showed that the relative proportion of lost foraging time from vessel exposure increased exponentially with prey depth. Whales were unable to compensate for lost feeding opportunities by increasing diving rate or swim speed, except when feeding within 10 to $15 \mathrm{~m}$ of the surface. Our results indicate that preventing vessels from entering within a $400 \mathrm{~m}$ radius around blue whales can help reduce the negative effects of marine recreational activities on blue whale foraging.
\end{abstract}

KEY WORDS: Disturbance $\cdot$ Behaviour $\cdot$ Whale-watching $\cdot$ Foraging $\cdot$ GLMM $\cdot$ GEE

\section{INTRODUCTION}

Vessel traffic may alter marine mammal behaviour through their physical presence, elevated underwater noise levels and exposure to collision risks (Richardson et al. 1995, Laist et al. 2001, Nowacek et al. 2007, Clark et al. 2009, Parsons 2012, Pirotta et al. 2015). Whale-watching, a form of vessel traffic in which boat operators and tourists specifically seek to interact with marine mammals, is a lucrative business that has developed rapidly and widely over the past decades (O'Connor et al. 2009). This type of activity has been repeatedly shown to elicit short-term be-

${ }^{*}$ Corresponding author: veronique.lesage@dfo-mpo.gc.ca havioural responses from a variety of marine mammal species (e.g. Richardson et al. 1995, Parsons 2012, Senigaglia et al. 2016 for reviews). Such changes in behaviour can result in increased energetic expenditures or decreased energetic gains (e.g. Gordon et al. 1992, Christiansen et al. 2014). When repeated or persistent, these activities have the potential to affect vital rates through changes in activity budget, loss of foraging opportunities, or reduction in mate or predator detection capacity by loss of acoustic space (e.g. Bejder et al. 2006, Williams et al. 2006, Lusseau \& Bejder 2007, Clark et al. 2009, Christiansen et al. 2013a,b, Symons et al. 2014).

(C) Fisheries and Oceans Canada 2017. Open Access under Creative Commons by Attribution Licence. Use, distribution and reproduction are unrestricted. Authors and original publication must be credited.

Publisher: Inter-Research · www.int-res.com 
Measuring short-term behavioural reactions of targeted individuals to vessel exposure is a common method to evaluate the effects of whale-watching and other activities. Often, the degree of response is inferred from changes in respiratory and diving patterns, activity budget, acoustic behaviour or movement metrics (Southall et al. 2007, Parsons 2012, Senigaglia et al. 2016). Marine mammals are airbreathing vertebrates, and thus behave as centralplace foragers, where the surface acts as the central place to which they must return after foraging trips at depth (Orians \& Pearson 1979, Kramer 1988). For most marine mammals, the time spent at the surface replenishing oxygen stores has a positive influence on the time they can allocate at depth during a subsequent foraging dive (Kooyman \& Ponganis 1998, Thompson \& Fedak 2001). Therefore, in cases where foraging represents the predominant activity, metrics related to respiratory patterns and dive time can be reasonable proxies for estimating loss of feeding opportunities associated with vessel interaction and the potential effects on vital rates (e.g. Christiansen \& Lusseau 2015).

Blue whales Balaenoptera musculus are considered capital breeders, provisioning their offspring using energy stores accumulated over earlier periods (Houston et al. 2007). During the fattening period, blue whales and other cetaceans occupy the St. Lawrence Estuary, Canada, where they spend most of their time feeding (Lesage et al. 2007, Doniol-Valcroze et al. 2012). High and recurrent densities of these cetaceans during the summer and fall have stimulated the development of a whale-watching industry consisting of approximately 40 vessels, offering several departures per day. Whale-watching and other recreational activities are regulated within the limits of the Saguenay-St. Lawrence Marine Park (see Fig. 1), where there are prohibitions for vessels to be within $400 \mathrm{~m}$ of whales listed as endangered or threatened under the Canadian Species at Risk Act, such as the blue whale and St. Lawrence Estuary beluga Delphinapterus leucas (Canada Gazette 2015a). In sectors outside the marine park, where most of the blue whale aggregations are located, whale-watching and other recreational activities are regulated via the Marine Mammal Regulations of the Fisheries Act, which prohibits disturbance without specifying a distance limit (Canada Gazette 2015b).

To assess the adequacy of the $400 \mathrm{~m}$ limit for mitigating potential effects from whale-watching and other vessel interactions on foraging blue whales, we report on their short-term behavioural responses to vessel proximity, using variables related to breathing and diving patterns. Empirical relationships between surface time, foraging time and the number of feeding opportunities while at depth have been documented for St. Lawrence Estuary blue whales (DoniolValcroze et al. 2011). Considering that foraging is their predominant activity in this area, with on average $68 \%$ of their time spent in this activity (T. DoniolValcroze \& V. Lesage unpubl. data), the chosen metrics are relevant for inferring losses of feeding opportunities as a result of vessel interactions.

\section{MATERIALS AND METHODS}

This study was conducted between July and September of 2006 and 2010, during peak blue whale abundance (Edds \& MacFarlane 1987) and whalewatching activities (Chion et al. 2009) in the St. Lawrence Estuary, Canada. Our study area corresponded to the sector located over the Laurentian Channel, between Cap Colombier and GrandesBergeronnes (Fig. 1). Weather permitting (i.e. Beaufort sea state $\leq 3$ and $>2 \mathrm{~km}$ visibility), a portion of this sector was searched for the presence of blue whales. The searched area was changed daily to ensure complete coverage of the study area at regular intervals. Observations were made from a $10 \mathrm{~m}$ rigid-hull inflatable vessel that was either moving at very low speed $\left(<3 \mathrm{~km} \mathrm{~h}^{-1}\right)$ or completely stationary.

Only 1 whale was followed at a time, and none of the followed individuals were part of a group as this would have led to uncertainty when measuring individual breathing and diving parameters. An observer was specifically tasked with recording the time of each breath taken by the focal animal. A second observer estimated the whale's position relative to our research vessel (i.e. its distance using naked eye or a range finder, and angle relative to magnetic north using binoculars with an integrated compass) at the beginning and end of each breathing sequence. At the end of each breathing sequence, this observer also noted the number and type of vessels other than our own (i.e. small or larger tour boat, recreational vessels, or merchant ships) that were observed within the following estimated distance categories from the focal whale: 0-400, 400-1000, 1000-2000, and $>2000 \mathrm{~m}$. In addition, the observer estimated the distance of the closest vessel to the whale at the time of its last breath; this distance was validated a posteriori using radar positioning of the vessel, and the whale's estimated position to allow further analysis of proximity effects, including categories within 0 to $400 \mathrm{~m}$ (e.g. see Fig. 2). Distance 


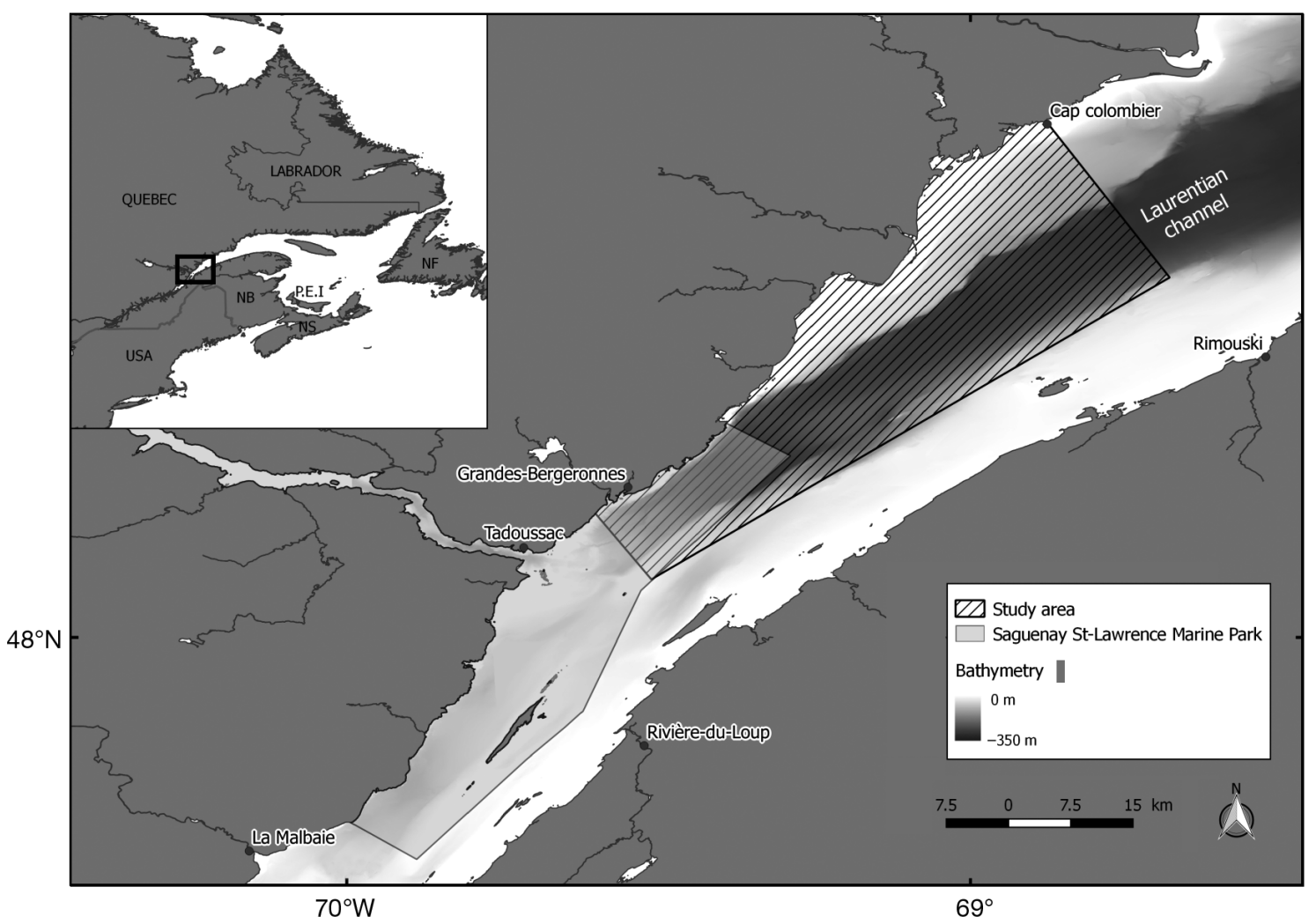

Fig. 1. Study area in the St. Lawrence Estuary, eastern Canada

estimates made by the naked eye were periodically calibrated with distances to objects or vessels measured using the radar system. A radar operator monitored vessel movements using target marking and movement tracking on the radar to characterize vessel abundance, type and position at the beginning and end of each breathing sequence. The position of our research vessel was logged automatically every 10 s using a Global Positioning System, and was used to calculate the whale position from estimated angle and relative distance. This information was then combined with radar-estimated positions of vessels to calculate the distance separating the nearest vessel from the whale at the beginning and end of each breathing sequence. It was assumed that errors in estimated distances were small relative to the defined distance categories.

Blue whales normally structure their surfacings into discrete bouts, with several shorter inter-breath intervals followed by a longer dive. Surface time was defined as the interval between the first and last breath; surface-feeding events not associated with a breath were considered as being part of dive time. Ensuring detection of the whale's first breath can be challenging, but is crucial for accurate behavioural measurement. To increase the probability of first-breath de- tection, we had 4 observers on the research vessel, each actively scanning and listening for the breath acoustic cue. Sudden movement of whale-watching vessels (when present) in the same direction was used as an additional detection cue. Surface sequences were discarded when whales were only detected due to sudden movement of whale-watching boats. Identification of the last breath of each sequence was facilitated by the tendency of blue whales to arch their back as they dive, showing their dorsal fin and, in some cases, the fluke. These cues, combined with an inter-breath interval several times longer than the previous ones, confirmed the end of the breathing sequence. In certain cases, such as when blue whales engaged in near-surface feeding and dove for short intervals, the end time of a breathing sequence was difficult to identify. Manual validation of surface times was made a posteriori by examining interbreath interval variability. For breathing sequences where start and end times were unambiguously determined by field observers, i.e. usually for sequences of several breaths following dives of several minutes, inter-breath interval averaged $14 \pm 6 \mathrm{~s}$ (mean $\pm \mathrm{SD}$ ), with a maximum of $50 \mathrm{~s}$. This maximum value was used to identify termination of a breathing sequence in cases where breaths were taken more irregularly. 
Follows were discarded when they were suspected to comprise more than 1 individual. Among the remaining follows, only those with complete data for at least 5 breathing sequences regardless of whether vessels were present or not were retained for analyses. Response variables used to describe blue whale behaviour included surface time (time between first and last breath), inter-breath interval, number of breaths and duration of the following dive. By definition, breathing sequences comprising only 1 breath were missing surface time and inter-breath interval. However, it was possible to estimate surface time for these single-breath sequences using a separate dataset of 10 blue whales also exposed to whale-watching activity in the same area in the early 2000s (DoniolValcroze et al. 2011). These whales had been equipped with archival tags that sampled depth $( \pm 0.25 \mathrm{~m})$ every $1 \mathrm{~s}$. Based on 6668 dives and associated surface times (defined as the time spent within $1 \mathrm{~m}$ of the surface), surface time for single breath averaged $6 \pm 2 \mathrm{~s}$.

Successive measures obtained from focal-followed individual whales are auto-correlated and considered pseudo-replicates. Failing to account for nonindependence of model residuals and autocorrelation generally results in underestimated uncertainty of model estimates. Both mixed-effect models and generalized estimating equation (GEE) can fit models to longitudinal/clustered data which include correlated responses (Liang \& Zeger 1986, Fieberg et al. 2009). Mixed-effect models are better suited for situations where heterogeneity in individual response is expected as a result of unmeasured factors, whereas GEEs are preferred when the population-averaged response is of primary interest. In the latter case, the distributional properties of the subjects are not included in the estimate of the main response, which depends exclusively on the covariates and not on the random effects (Zuur et al. 2009).

In the present study, 2 specific effects on whale behaviour were of interest: (1) vessel presence within $2000 \mathrm{~m}$ of focal whales and (2) distance of the nearest vessel to the whale. A mixed-effects model was the logical choice for examining these effects since factors such as diving depth and behaviour (e.g. transit vs. foraging) were not measured in our study, and likely influenced blue whale surface and dive times (Doniol-Valcroze et al. 2011). A generalized linear mixed model (GLMM) with a Gaussian error distribution and an identity link function was used to model blue whale response to the presence of vessels. The focal individual was included as a random effect. Eighteen follows comprising at least 8 breathing sequences in total, and at least 4 breathing sequences for each of the 2 treatments (with and without vessels within $2000 \mathrm{~m}$ ) were included in the analysis. While it is plausible that some individuals were followed more than once during the study, there is no means to verify this given our remote position during follows; therefore, follows were assumed independent. Likelihood ratio tests comparing the null model with the model including vessel presence as a fixed effect were used to validate $t$-test results.

The effect of vessel distance on whale behaviour could not be examined using a GLMM approach due to the lack of individual behavioural data across all distance categories. A GEE-GLM approach was therefore adopted to account for autocorrelation in responses of individual whales, with the caveat that this method provides only population-averaged parameter estimates for each distance category, i.e. it does not account for potential effects of behaviour and foraging depth on responses from individual whales (Wedderburn 1974). The GEE approach also assumes independence among clusters, i.e. the distance categories of individual whales. However, we strongly suspected non-independence among clusters, since whales exhibiting a strong response toward distant vessels were also likely to respond strongly at closer distances, or a whale not responding to a vessel at $400 \mathrm{~m}$ was also unlikely to respond to vessels located further away. To comply with the cluster independence assumption, the 11 whales unexposed to vessels were included as independent clusters representing the ' $2000 \mathrm{~m}+$ ' distance category, and the 22 whales exposed to vessels at $<2000$ m were each made an independent cluster by selecting observations only for the distance category with the highest sample size. Since the correlation structure for the errors within each cluster was uncertain, a working independence model was applied as it is preferred over the specification of a correlation structure in such cases (Pan 2001, Fieberg et al. 2009). This approach generally leads to efficient model coefficients and uses robust sandwich estimators to produce realistic standard errors. To ensure that the selected correlation structure was adequate, we repeated the analysis assuming an 'exchangeable' correlation structure, i.e. we assumed within-subject observations were equally correlated. Model selection was based on quasi-likelihood under the independence criterion (QIC). This is an extension of Akaike's information criterion (AIC) that allows the comparison of covariance matrices under GEE models to the covariance matrix generated from a model that assumes no correlation within clusters (Pan 2001). The lower the QIC value, the more appropriate the correlation structure 
used to fit the data. Model adequacy was assessed based on a Wald-Wolfowitz run test for randomness of residuals (Chang 2000), and a scale parameter for dispersion (Zuur et al. 2009). Repeated Wald tests were carried out to assess the significance of distance categories, using the 0 to $400 \mathrm{~m}$ distance category as a reference (Hardin \& Hilbe 2003).

We also assessed whether blue whales were more responsive to the relative distance of a vessel at the start or at the end of a breathing sequence. The relationship between distance of the whale to the nearest vessel (measured by radar, a continuous variable) and each of the response variables was examined using GEE-GLMs. Separate analyses were conducted for response variables at the start and end of a breathing sequence, ensuring independency among clusters. Wald tests were carried out on each model to evaluate covariate significance.

Statistical analyses were performed using the $\mathrm{R}$ software (version 3.3.0; R Development Core Team 2008), and the contributed packages 'geepack' v.1.2-0 (Højsgaard et al. 2006), 'adehabitat' v.1.8-18 (Calenge 2006), and 'lme4' v.1.1-12 (Bates et al. 2015). Unless otherwise noted, average results are presented $\pm \mathrm{SD}$.

\section{RESULTS}

A total of 43 blue whale encounters and $131 \mathrm{~h}$ of observation were made in 2006 and 2010 (31 encounters in 2006 for $34 \mathrm{~d}$ of effort and 12 encounters in 2010 over $36 \mathrm{~d}$ ). In all, 33 focal follows and $106 \mathrm{~h}$ of data qualified for analysis. The average duration of focal follow was $3.25 \mathrm{~h}$ (range: 0.5 to $10.75 \mathrm{~h}$ ). Whales spent on average $17 \pm 4.4 \%$ ( $\mathrm{n}=33$ follows) of their time at the surface.

Vessels occurred $<2000 \mathrm{~m}$ from focal whales in 23 (70\%) of the follows, $91 \%$ of which were whalewatching vessels. Exposure to vessels varied among whales from 5 to $100 \%$ of observation time, and averaged 59 $\pm 31 \%$. A maximum of 8 vessels were observed simultaneously within $400 \mathrm{~m}$ from blue whales, or 16 vessels when considering radiuses of 1000 or $2000 \mathrm{~m}$. However, median values of $1 \pm 1.2$ vessels within $400 \mathrm{~m}(\mathrm{n}=224), 1 \pm 1.6$ vessels within $1000 \mathrm{~m}(\mathrm{n}=317)$, and 2 \pm 1.6 vessels within $2000 \mathrm{~m}(\mathrm{n}=395)$ indicate that the number of vessels around whales was generally low. However, large variances around mean estimates (Table 1) indicate that larger aggregations of vessels around whales were not rare.

Vessels affected blue whale diving patterns when present at distances $<2000 \mathrm{~m}$. Significant reductions in surface time, dive time and number of breaths per breathing sequence were documented compared to when vessels were absent or at distances $>2000 \mathrm{~m}$ (Table 2). Examining surface and dive parameters by distance category using the 33 follows as independent clusters revealed that response variables were each best modelled (i.e. had lower QICs) using GEEs that assumed an 'independence' correlation structure among residuals (data not shown); only results from these models are presented. The effect of vessel distance on whale behavioural response was significant for surface time and number of blows (GEEGLM, Wald test, $\mathrm{p}<0.05)$, marginally insignificant for dive time $(p=0.07)$, and not significant for interbreath interval $(\mathrm{p}>0.05)$ and increased with vessel proximity (Fig. 2). In general, it was only once vessels were within $400 \mathrm{~m}$ of a whale that response variables became significantly different compared to when no vessels were present within $2000 \mathrm{~m}$ of the whales (Fig. 2). At distances $<400 \mathrm{~m}$, surface and dive times were on average 49 and $36 \%$ shorter, respectively, with a $51 \%$ reduction in the number of breaths. These paired comparisons were statistically significant for surface time and number of breaths (Wald tests, all $\mathrm{p} \leq 0.05$ ), and marginally insignificant for dive time (Wald test, $\mathrm{p}=0.059$ ).

The relative nearest-vessel distance to a whale at the start of a breathing sequence also had a significant effect on all response variables (GEE-GLM, $\mathrm{n}=$ 23 clusters or whales; Wald statistic, $\chi^{2}=5.3$ to 8.5 , all $\mathrm{p} \leq 0.02)$ except inter-breath interval $\left(\chi^{2}=0.11, \mathrm{p}=\right.$

Table 1. Effects of vessel presence within $2000 \mathrm{~m}$ of blue whales Balaenoptera musculus in the St. Lawrence Estuary $(\mathrm{n}=18)$ on various behavioural parameters estimated using generalized linear mixed models (GLMMs) with focal individual as a random effect. The effect of the predictor (vessel presence or absence) on each response variable is expressed using coefficient estimates $(\beta)$, standard error SE $(\beta), t$-value and significance level ( $p_{\text {; }} t$-test using Satterthwaite approximation for degrees of freedom)

\begin{tabular}{|llrrrr|}
\hline Response variable & Predictor & Coef. $(\beta)$ & SE $(\beta)$ & $t$-value & $p$ \\
\hline Surface time & Intercept & 1.26 & 0.15 & 8.3 & 0.0001 \\
& Vessel effect & -0.18 & 0.04 & -4.0 & 0.0001 \\
Dive time & Intercept & 7.28 & 0.88 & 8.2 & 0.0001 \\
& Vessel effect & -0.41 & 0.19 & -2.2 & 0.029 \\
Inter-breath interval & Intercept & 0.23 & 0.01 & 26.9 & 0.0001 \\
& Vessel effect & -0.01 & 0.01 & -1.53 & 0.13 \\
Number of breaths & Intercept & 5.50 & 0.68 & 8.07 & 0.0001 \\
& Vessel effect & -0.60 & 0.16 & -3.79 & 0.0001 \\
\hline
\end{tabular}


Table 2. Parameters used to evaluate the effect of reducing mean surface and dive times on the time available for foraging by blue whales Balaenoptera musculus in a food patch located at depths varying from 1 to $150 \mathrm{~m}$, and calculated for a single dive $\left(F_{t}\right)$ and for a $1 \mathrm{~h}$ foraging bout $\left(F_{\text {tot }}\right) . F_{t}$ and $F_{\text {tot }}$ over the 1 to $150 \mathrm{~m}$ depth range are presented in Fig. 3. Values provided for dive time and surface time were obtained using a generalized estimating equations for generalized linear model type of data

(GEE-GLM) approach and the 33 follows as independent clusters (Fig. 2)

\begin{tabular}{|c|c|c|c|c|}
\hline \multirow[t]{2}{*}{ Parameter } & \multirow[t]{2}{*}{ Definition } & \multicolumn{2}{|c|}{ Value if distance to nearest vessel } & \multirow{2}{*}{$\begin{array}{c}\text { Change } \\
(\%)\end{array}$} \\
\hline & & $>2000 \mathrm{~m}$ & $\leq 400 \mathrm{~m}$ & \\
\hline$D_{t}$ & Observed dive time (min) & 6.37 & 4.05 & -36 \\
\hline$S_{t}$ & Observed surface time (min) & 1.25 & 0.64 & -49 \\
\hline $\mathrm{DC}$ & Observed dive cycle time $(\min )\left(D_{t}+S_{t}\right)$ & 7.62 & 4.69 & -38 \\
\hline$N_{\text {dives }}$ & Number of dives over $1 \mathrm{~h}(60 / \mathrm{DC})$ & 7.87 & 12.8 & 38 \\
\hline$V$ & Transit speed $\left(1 \mathrm{~m} \mathrm{~s}^{-1}\right.$ or $\left.1.5 \mathrm{~m} \mathrm{~s}^{-1}\right)$ & & & \\
\hline$T_{t}$ & Transit time $(2 \times$ depth $/ V)$ & & & \\
\hline$F_{t}$ & Time left for foraging $\left(D_{t}-T_{t}\right)$ & & & \\
\hline$F_{\text {tot }}$ & Total time $(\mathrm{min})$ for foraging over $1 \mathrm{~h}\left(F_{t} \times N_{\text {dives }}\right)$ & & & \\
\hline
\end{tabular}
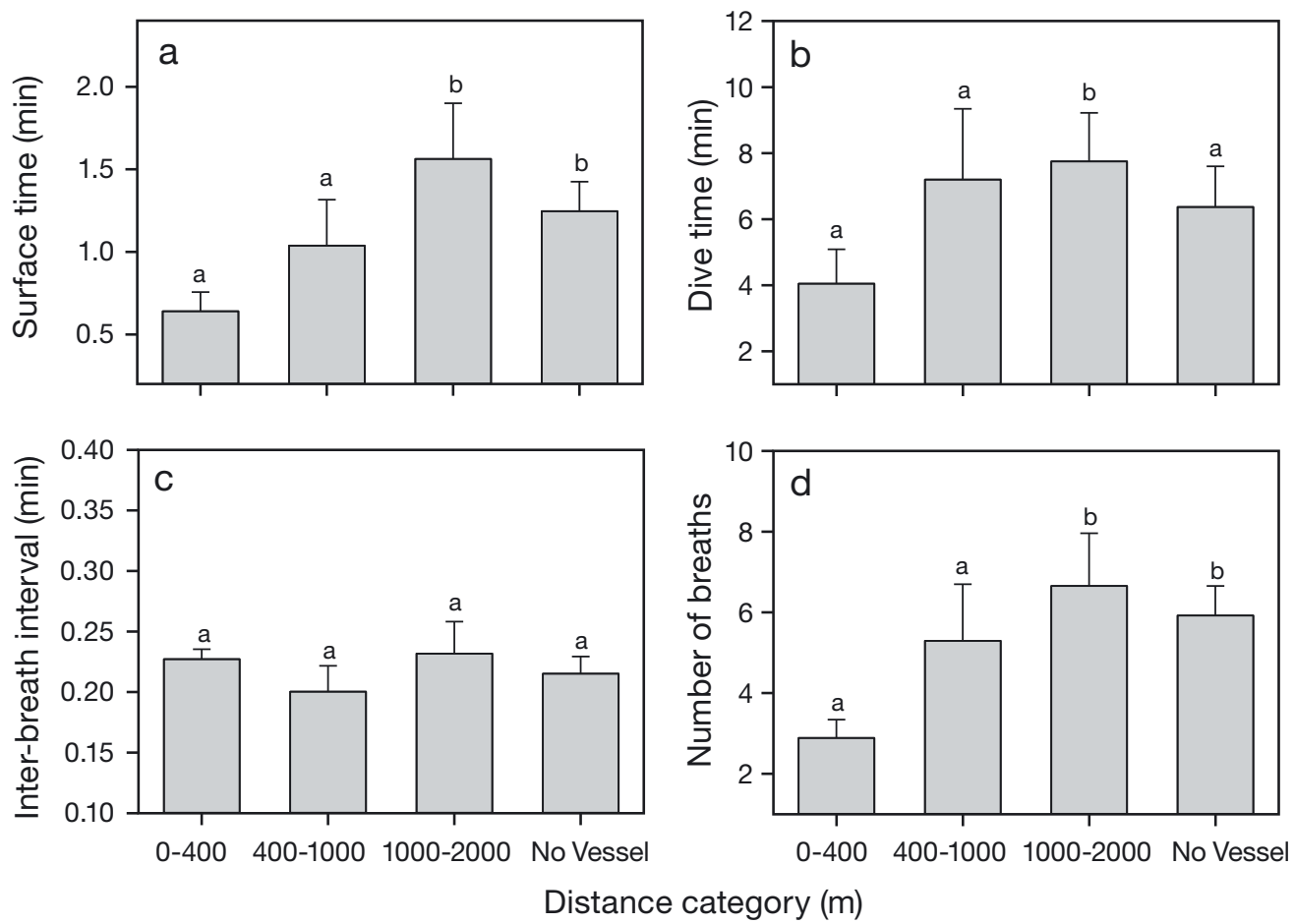

Fig. 2. Effect of vessel distance to blue whales Balaenoptera musculus: mean ( \pm SE) (a) surface time, (b) post-exposure dive time, (c) inter-breath interval and (d) number of breaths per breathing sequence, assessed using generalized estimating equations with independence correlation structure. Comparisons among distance categories are relative to the 0 to $400 \mathrm{~m}$ category. Identical letters above bars indicate lack of significant difference (Wald tests, $\mathrm{p}>0.05$ )

0.74). However, no significant relationship was detected when considering the relative nearest-vessel distance to a whale at the end of a breathing sequence (GEE-GLM, $\mathrm{n}=23$ clusters; $\chi^{2}=0.05$ to 2.6 , all $\mathrm{p}>0.05)$, indicating that blue whale behavioural response to a vessel was driven by the relative proximity of the vessel at the time of surfacing, not at the time of diving.

\section{DISCUSSION}

For air-breathing animals living in aquatic environments, an event that reduces time spent at the surface and the number of breaths taken can limit diving capacity, and therefore, foraging time. Because oxygen is acquired at the surface with diminishing returns, recovery times increase rapidly with leng- 

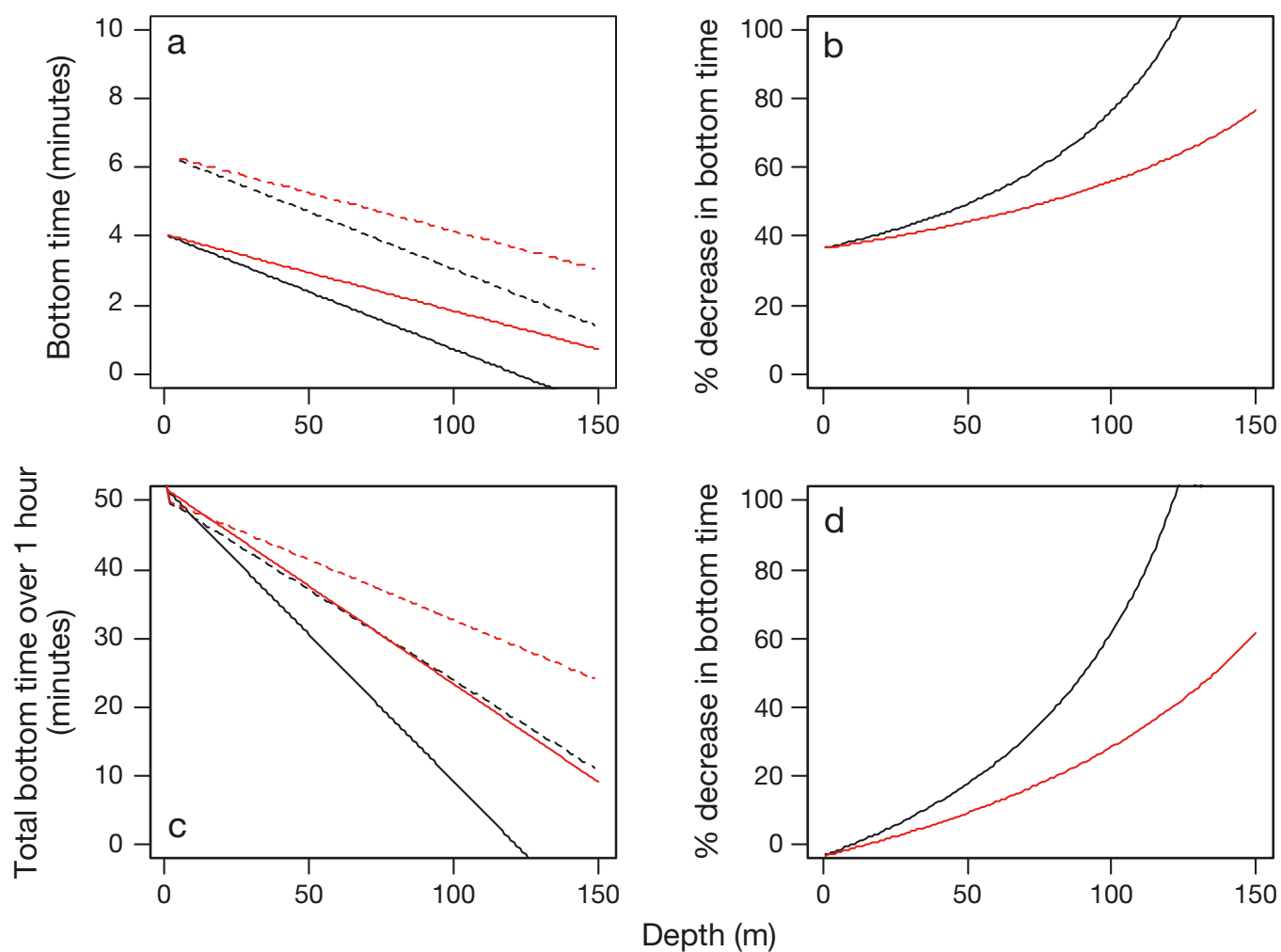

Fig. 3. Change in time available for blue whale Balaenoptera musculus foraging (foraging time) as a function of depth during $(\mathrm{a}, \mathrm{b})$ single dives and (c,d) a $1 \mathrm{~h}$ foraging bout (foraging time per bout), when vessels were present within $400 \mathrm{~m}$ of whales (solid line) and when vessels were absent within a $2000 \mathrm{~m}$ radius (dashed line). Change in time available for foraging is expressed as absolute time in (a) and (c), and as percent decrease in (b) and (d), as a result of vessel presence when considering the average transit speed ( $1 \mathrm{~m} \mathrm{~s}^{-1}$; black line) and maximum transit speed $\left(1.5 \mathrm{~m} \mathrm{~s}^{-1}\right.$; red line) of blue whales

thening of dives (Kramer 1988, Kooyman \& Ponganis 1998). Thus, the effects of disrupting surface behaviour may be exacerbated in cases where animals need prolonged at-surface recovery time to perform long or deep dives to reach and efficiently exploit food patches (Thompson \& Fedak 2001). This is exemplified in sperm whales, a deep- and long-diving species that consequently requires long recovery times at the surface, and for which a $17 \%$ reduction in surface time is estimated to induce a $36 \%$ reduction in foraging time (Gordon et al. 1992).

St. Lawrence Estuary blue whales usually forage at greater depths during the day than at night, although near-surface foraging can occur during the daytime (Doniol-Valcroze et al. 2011). Whale-watching activities operate exclusively during the day, when blue whale dives are likely the deepest and recovery times at the surface are the longest. Blue whales employ a relatively costly foraging strategy called lunge feeding (Acevedo-Gutiérrez et al. 2002, Goldbogen et al. 2012). This foraging tactic might lead to shorter than expected dive times (Croll et al. 2001) and regular exhaustion of oxygen stores, placing additional con- straints on surface recovery time (Potvin et al. 2012). In St. Lawrence Estuary blue whales, optimal dive time and theoretical aerobic dive limit (TADL) converge with increasing depth, because for deeper dives (generally during daytime) a greater amount of time is spent travelling through the water column, thereby constricting time and oxygen stores left available for foraging at depth (Doniol-Valcroze et al. 2011). How often blue whales in the St. Lawrence Estuary rely on anaerobic metabolism as a result of exceeding their TADL is unknown. An oxygen debt can be accumulated over a few dives and repaid later, e.g. at the end of a foraging bout, as observed in some otariids (e.g. Fahlman et al. 2008). However, in the present study, the reduction in dive duration was observed immediately following vessel exposure, suggesting that disruption of breathing sequences and associated reduction in the number of breaths taken has an immediate consequence on dive duration in blue whales.

Blue whales in the St. Lawrence Estuary spend on average $68 \pm 14 \%$ of their time foraging during summer (T. Doniol-Valcroze \& V. Lesage unpubl. data). 
Foraging is thus their primary activity. This implies that the observed reduction in dive time translates to foraging time in most of the blue whales followed, and may result in lost foraging opportunities. The $36 \%$ reduction in dive time documented when vessels were within $400 \mathrm{~m}$ of whales likely meant a greater than $36 \%$ reduction in foraging time for 2 reasons: first, foraging depth is dictated by where krill densities are located. Thus, foraging depth likely remains constant during a foraging bout (i.e. whales cannot choose a different foraging depth to compensate for reduced dive times). Second, a relatively fixed amount of time is needed to reach the preferred foraging depth and food patch. Given that surface time was also shorter in disturbed whales, one could argue that blue whales can compensate for shorter foraging time during a dive by performing more dives during a feeding bout. However, this would entail proportionally more time spent in transit, and hence higher energy expenditure. Blue whales could also increase their transit speed to increase time spent at depth, although this could ultimately decrease net energy gain from foraging by increasing cost of transport.

The effect of changing transit speed or increasing diving rate on foraging time can be explored using dive duration and surface time documented in presence and absence of vessels, while making no assumption about optimality or target foraging depth. Transit speeds have been estimated for blue whales, and average $1 \mathrm{~m} \mathrm{~s}^{-1}$ with maxima of around $1.5 \mathrm{~m} \mathrm{~s}^{-1}$ (Doniol-Valcroze et al. 2011, Goldbogen et al. 2011, McKenna et al. 2015). Let us first consider scenarios where transit speed is unaltered by vessel exposure, and fixed at $1 \mathrm{~m} \mathrm{~s}^{-1}$. When accounting for transit time to reach a given depth varying between 1 and $150 \mathrm{~m}$, time available for foraging during single dives decreases linearly with depth, and is consistently shorter when vessels are present within $400 \mathrm{~m}$ of blue whales than when they are absent from a $2000 \mathrm{~m}$ radius around them (Fig. 3a). Based on our results, whales that are not exposed to vessels can reach food patches located at $150 \mathrm{~m}$ or deeper and still have time to forage to some extent, whereas whales within $400 \mathrm{~m}$ of vessels have no time left to forage at depths beyond $121 \mathrm{~m}$ (Fig. 3a). The relative proportion of lost foraging time as a result of vessel exposure $(<400 \mathrm{~m}$ ) increases exponentially with depth (Fig. 3b). Although shorter dive times and surface sequences allow for an increased diving rate, the effective foraging time remains a function of the overall time spent at depth foraging during the entire bout. For a $1 \mathrm{~h}$ foraging bout, and assuming transit speed is con- stant at $1 \mathrm{~m} \mathrm{~s}^{-1}$, a total of 7.9 dive cycles (surface + dive time) are performed on average in the absence of vessels. This number could theoretically almost double to 12.8 dive cycles $\mathrm{h}^{-1}$ if blue whales increased their diving rate in response to vessels within $400 \mathrm{~m}$ (Table 2). However, given that transit time is a fixed component for each dive, time available for foraging in a food patch still decreases with depth when integrated over a $1 \mathrm{~h}$ foraging bout, except when blue whales are surface-feeding (Fig. 3c). For instance, for a blue whale feeding at a $10 \mathrm{~m}$ depth or less, the decrease in foraging time per dive can theoretically be fully compensated by increasing the number of dives performed during the $1 \mathrm{~h}$ foraging bout, for a possible total increase in foraging time of up to $3 \%$ (Fig. 3c). However, at greater depth, foraging time lost during individual dives cannot be fully compensated by increasing diving rate. Increasing transit speed to $1.5 \mathrm{~m} \mathrm{~s}^{-1}$ increases depth at which full compensation is possible to $15 \mathrm{~m}$ (Fig. 3a). While some blue whales forage at these shallow depths during daytime in the St. Lawrence Estuary, the majority of individuals target deeper food patches, generally between 30 and $100 \mathrm{~m}$, with a maximum foraging depth documented at $128 \mathrm{~m}$ (Doniol-Valcroze et al. 2011).

We showed that even if blue whales increase transit speed and diving rate, they cannot compensate for shorter dive time over most of the range of targeted depths. A meta-analysis has documented cetacean response to whale-watching and indicates that a shift in activity budget towards decreased foraging and resting times is a fairly consistent response to vessel exposure across cetaceans, including blue whales (Senigaglia et al. 2016). For instance, fin whales Balaenoptera physalus foraging off the coast of Maine, USA, in proximity to whale-watching vessels decreased their surface time and number of breaths by 9 and $10 \%$, respectively, and their dive duration by $14 \%$ (Stone et al. 1992). Icelandic minke whales Balaenoptera acutorostrata also interrupted their foraging activity in addition to reducing their inter-breath interval as a result of exposure to whale-watching vessels (Christiansen et al. 2013a). Documented responses of blue whales exposed to vessels or midfrequency military sonars also suggest that they are unlikely to increase diving rates or swim speed as compensatory strategies to maintain foraging time (Goldbogen et al. 2013, McKenna et al. 2015). Blue whales decreased deep-foraging when exposed to military sonars, whereas they tended to perform 'response dives' when exposed to collision risks (McKenna et al. 2015). Response dives are typically 
shallow (<30 m), involve no foraging (no lunges) and have slower descent rates compared to 'undisturbed' foraging dives. Some of the dives following vessel exposure in our study might have been response dives. Unless food patches were located within $30 \mathrm{~m}$ of the surface, response dives likely represented a full loss of foraging time given that blue whales were unable to reach feeding depth.

A possible effect of our research vessel on the behaviour of blue whales cannot be excluded. However, we considered this effect to be relatively constant and unlikely to bias our results given that the distance of our vessel to the whale (which varied from 400 to $800 \mathrm{~m}$ ) invariably fell into a single 400 to $1000 \mathrm{~m}$ distance category we set, and was outside that of closest vessel proximity to whales (i.e. $\leq 400 \mathrm{~m}$ ), where the most significant behavioural changes were documented. Moreover, our vessel was not moving during blue whale surface sequences, to further minimize disturbance.

Being the largest animals on Earth with a highly specialized diet (stenophagous), blue whales have the greatest absolute metabolic demands, and their foraging behaviour is strongly driven by the availability and depth of dense krill patches (Goldbogen et al. 2015). As a result, they are particularly vulnerable to changes in prey abundance or distribution, or prey access (Croll et al. 1998, Clapham et al. 1999, Acevedo-Gutiérrez et al. 2002). Repeated disturbance can reduce prey access and overall foraging success by limiting dive time if oxygen stores cannot be adequately replenished at the surface, or can force whales to move to areas of sub-optimal quality with less dense or less accessible patches of krill. Disruption of breathing sequence and thus impairment of oxygen replenishment over short periods of time may possibly be compensated by increased feeding rates at a later time, as proposed for some odontocete species (e.g. New et al. 2013). The likelihood of effects on the fitness of individuals depends on their ability to compensate and varies according to specific ecological and social conditions (New et al. 2013). In true capital breeders such as Balaenopteridae, the degree of flexibility to cope with foraging disruption may not be as large as in small odontocetes. In Icelandic minke whales, blubber volume increases linearly over the feeding season (Christiansen et al. 2013c), suggesting that their aim is to put on as much fat as possible during the feeding season to complete their annual cycle. Blue whales likely have limited flexibility in coping with repeated foraging disruption given that foraging already constitutes a large proportion of their activity budget in the St. Lawrence Estuary.
The majority of blue whales encountered in this study were exposed to whale-watching vessels, which were present during more than half of the observation period on average. Given the intense whale-watching activity, small territory and low number of individuals present in the St. Lawrence Estuary at any given time (usually less than 8 or 10), each blue whale is exposed possibly daily and for several hours a day to this activity during their summer feeding season. Effects of whale-watching activities on surface and diving patterns were particularly notable when vessels occurred within $400 \mathrm{~m}$ of the whales, but were perceptible when vessels were at distances up to $1000 \mathrm{~m}$. Behavioural responses of blue whales in this study were of a larger magnitude compared to those documented in fin and minke whales from other areas (Stone et al. 1992, Christiansen et al. 2013a), suggesting that this population might be particularly sensitive to disruptive activities when animals are foraging. Recent reviews of behavioural responses of marine mammals to various sources of anthropogenic noise and activity have concluded that behavioural response is highly context-specific (Gill et al. 2001, Southall et al. 2007, Ellison et al. 2012, Gomez et al. 2016). There is a need to investigate whether foraging depth and frequency of exposure to vessels affect the behavioural response of blue whales (Laist et al. 2001, Goldbogen et al. 2013). A larger sample size would have allowed some of these effects to be explored, as well as other contextual aspects such as the effect of vessel speed or angle of movement relative to the whale, vessel type, abundance and configuration around the whale. Nonetheless, our results indicate that preventing vessels from entering within a $400 \mathrm{~m}$ radius around blue whales can help reduce the negative effects of marine recreational activities on foraging blue whales. This exclusion zone, which is currently in place in the Saguenay-St. Lawrence Marine Park, could be extended elsewhere.

A direct assessment of the impact of whale-watching on foraging success was not possible in this study. However, considering the intensity of whale-watching activities in the region and of the dive time reductions documented in this study, it is warranted to proceed with a study of the cumulative effects of chronic exposure to vessels on vital rates of blue whales (e.g. New et al. 2013, 2014, Christiansen \& Lusseau 2015, Christiansen et al. 2015, King et al. 2015). The application of such models to St. Lawrence Estuary blue whales would help determine the threshold beyond which whale-watching or other marine recreational activities may reduce fitness and have population-level effects. 
Acknowledgements. We thank Y. Morin, S. Turgeon, G. Larrivée, C. Bajzak, J. Bernier, and P. Tremblay for assistance with data collection, and K. Gavrilchuk for proof-reading the manuscript. This study was funded by the Species at Risk and Marine Protected Area programs of Fisheries and Oceans Canada, and the Saguenay-St. Lawrence Marine Park.

\section{LITERATURE CITED}

Acevedo-Gutiérrez A, Croll DA, Tershy BR (2002) High feeding costs limit dive time in the largest whales. J Exp Biol 205:1747-1753

Bates D, Maechler M, Bolker B, Walker S (2015) Fitting linear mixed-effects models using lme4. J Stat Softw 67:1-48

* Bejder L, Samuels A, Whitehead H, Gales N and others (2006) Decline in relative abundance of bottlenose dolphins exposed to long-term disturbance. Conserv Biol 20: 1791-1798

Calenge C (2006) The package adehabitat for the R software: a tool for the analysis of space and habitat use by animals. Ecol Modell 197:516-519

Canada Gazette (2015a) Marine activities in the SaguenaySt. Lawrence marine park regulations SOR/2002-76. http://laws-lois.justice.gc.ca/PDF/SOR-2002-76.pdf (accessed 5 June 2016)

* Canada Gazette (2015b) Marine Mammal Regulations SOR/93-56. http://laws-lois.justice.gc.ca/PDF/SOR-93-56. pdf (accessed 5 June 2016)

* Chang YC (2000) Residuals analysis of the generalized linear models for longitudinal data. Stat Med 19:1277-1293

Chion C, Turgeon S, Michaud R, Landry JA (2009) Portrait de la navigation dans le parc marin du Saguenay-SaintLaurent: caractérisation des activités sans prélèvement de ressources entre le 1er mai et le 31 octobre 2007. École de technologie supérieure, Université de Montréal and the GREMM, Montréal

Christiansen F, Lusseau D (2015) Linking behavior to vital rates to measure the effects of non-lethal disturbance on wildlife. Conserv Lett 8:424-431

* Christiansen F, Rasmussen M, Lusseau D (2013a) Whale watching disrupts feeding activities of minke whales on a feeding ground. Mar Ecol Prog Ser 478:239-251

Christiansen F, Rasmussen MH, Lusseau D (2013b) Inferring activity budgets in wild animals to estimate the consequences of disturbances. Behav Ecol 24:1415-1425

* Christiansen F, Vikingsson GA, Rasmussen M, Lusseau D (2013c) Minke whales maximise energy storage on their feeding grounds. J Exp Biol 216:427-436

* Christiansen F, Rasmussen M, Lusseau D (2014) Inferring energy expenditure from respiration rates in minke whales to measure the effects of whale watching boat interactions. J Exp Mar Biol Ecol 459:96-104

* Christiansen F, Bertulli CG, Rasmussen MH, Lusseau D (2015) Estimating cumulative exposure of wildlife to nonlethal disturbance using spatially explicit capture-recapture models. J Wildl Manag 79:311-324

Clapham PJ, Young SB, Brownell RL (1999) Baleen whales: conservation issues and the status of the most endangered populations. Mammal Rev 29:37-62

Clark CW, Ellison WT, Southall BL, Hatch L, Van Parijs SM, Frankel A, Ponirakis D (2009) Acoustic masking in marine ecosystems: intuitions, analysis, and implication. Mar Ecol Prog Ser 395:201-222
Croll DA, Tershy BR, Hewitt RP, Demer DA and others (1998) An integrated approach to the foraging ecology of marine birds and mammals. Deep-Sea Res II 45: 1353-1371

Croll DA, Acevedo-Gutierrez A, Tershy BR, Urban-Ramirez J (2001) The diving behavior of blue and fin whales: Is dive duration shorter than expected based on oxygen stores? Comp Biochem Physiol A Mol Integr Physiol 129: 797-809

*Doniol-Valcroze T, Lesage V, Giard J, Michaud R (2011) Optimal foraging theory predicts diving and feeding strategies of the largest marine predator. Behav Ecol 22: 880-888

* Doniol-Valcroze T, Lesage V, Giard J, Michaud R (2012) Challenges in marine mammal habitat modelling: evidence of multiple foraging habitats from the identification of feeding events in blue whales. Endang Species Res 17:255-268

Edds PL, MacFarlane JA (1987) Occurrence and general behavior of balaenopterid cetaceans summering in the St. Lawrence Estuary. Can J Zool 65:1363-1376

* Ellison WT, Southall BL, Clark CW, Frankel AS (2012) A new context-based approach to assess marine mammal behavioral responses to anthropogenic sounds. Conserv Biol 26:21-28

Fahlman A, Svard C, Rosen DAS, Jones DR, Trites AW (2008) Metabolic costs of foraging and the management of $\mathrm{O}_{2}$ and $\mathrm{CO}_{2}$ stores in Steller sea lions. J Exp Biol 211:3573-3580

Fieberg J, Rieger RH, Zicus MC, Schildcrout JS (2009) Regression modelling of correlated data in ecology: subject-specific and population averaged response patterns. J Appl Ecol 46:1018-1025

*Gill JA, Norris K, Sutherland WJ (2001) Why behavioural responses may not reflect the population consequences of human disturbance. Biol Conserv 97:265-268

Goldbogen JA, Calambokidis J, Oleson E, Potvin J, Pyenson ND, Schorr G, Shadwick RE (2011) Mechanics, hydrodynamics and energetics of blue whale lunge feeding: efficiency dependence on krill density. J Exp Biol 214: 131-146

Goldbogen JA, Calambokidis J, Croll DA, McKenna MF and others (2012) Scaling of lunge-feeding performance in rorqual whales: mass-specific energy expenditure increases with body size and progressively limits diving capacity. Funct Ecol 26:216-226

Goldbogen JA, Southall BL, DeRuiter SL, Calambokidis J and others (2013) Blue whales respond to simulated midfrequency military sonar. Proc R Soc B 280:20130657

* Goldbogen JA, Hazen EL, Friedlaender AS, Calambokidis J, DeRuiter SL, Stimpert AK, Southall BL (2015) Prey density and distribution drive the three-dimensional foraging strategies of the largest filter feeder. Funct Ecol 29:951-961

*Gomez C, Lawson JW, Wright AJ, Buren AD, Tollit D, Lesage V (2016) A systematic review on the behavioural responses of wild marine mammals to noise: the disparity between science and policy. Can J Zool 94:801-819

Gordon J, Leaper R, Harthley FG, Chappell O (1992) Effects of whale-watching vessels on the surface and underwater acoustic behaviour of sperm whales off Kaikoura, New Zealand. Science \& Research Series No. 52, Department of Conservation, Wellington. www.doc.govt.nz/ documents/science-and-technical/sr52.pdf

Hardin JW, Hilbe JM (2003) Generalized estimating equations. CRC Press, Boca Raton, FL 
Højsgaard S, Halekoh U, Yan J (2006) The R package geepack for generalized estimating equations. J Stat Softw 15:1-11

Houston AI, Stephens PA, Boyd IL, Harding KC, McNamara JM (2007) Capital or income breeding? A theoretical model of female reproductive strategies. Behav Ecol 18: 241-250

King SL, Schick RS, Donovan C, Booth CG, Burgman M, Thomas L, Harwood J (2015) An interim framework for assessing the population consequences of disturbance. Methods Ecol Evol 6:1150-1158

Kooyman GL, Ponganis PJ (1998) The physiological basis of diving to depth: birds and mammals. Annu Rev Physiol 60:19-32

Kramer DL (1988) The behavioral ecology of air breathing by aquatic animals. Can J Zool 66:89-94

KLaist DW, Knowlton AR, Mead JG, Collet AS, Podesta M (2001) Collisions between ships and whales. Mar Mamm Sci 17:35-75

Lesage V, Gosselin JF, Hammill MO, Kingsley MCS, Lawson JW (2007) Ecologically and biologically significant areas (EBSAs) in the Estuary and Gulf of St. Lawrence: a marine mammal perspective. Canadian Science Advisory Secretariat Research Document 2007/046 available at www. dfo-mpo.gc.ca/csas

Liang KY, Zeger SL (1986) Longitudinal data analysis using generalized linear models. Biometrika 73:13-22

Lusseau D, Bejder L (2007) The long-term consequences of short-term responses to disturbance. Experiences from whalewatching impact assessment. Int J Comp Psychol 20:228-236

McKenna MF, Calambokidis J, Oleson EM, Laist DW, Goldbogen JA (2015) Simultaneous tracking of blue whales and large ships demonstrates limited behavioral responses for avoiding collision. Endang Species Res 27: 219-232

New LF, Harwood J, Thomas L, Donovan C and others (2013) Modelling the biological significance of behavioural change in coastal bottlenose dolphins in response to disturbance. Funct Ecol 27:314-322

New LF, Clark JS, Costa DP, Fleishman E and others (2014) Using short-term measures of behaviour to estimate long-term fitness of southern elephant seals. Mar Ecol Prog Ser 496:99-108

Nowacek DP, Thorne LH, Johnston DW, Tyack PL (2007) Responses of cetaceans to anthropogenic noise. Mammal Rev 37:81-115

O'Connor SO, Campbell R, Cortez H, Knowles T (2009) Whale-watching worldwide: tourism numbers, expenditures and expanding economic benefits. A special report from the International Fund for Animal Welfare. IFAW, Yarmouth, MA. www.ifaw.org/sites/default/files/whale_

Editorial responsibility: David Lusseau, Aberdeen, UK watching_worldwide.pdf (accessed 29 June 2016)

Orians GH, Pearson NE (1979) On the theory of central place foraging. In: Horn DJ, Stairs GR, Mitchell RD (eds) Analysis of ecological systems. Ohio State University Press, Columbus, OH, p 155-177

* Pan W (2001) Akaike's information criterion in generalized estimating equations. Biometrics 57:120-125

Parsons ECM (2012) The negative impacts of whale-watching. J Mar Biol 2012:807294

Pirotta E, Thompson PM, Cheney B, Donovan CR, Lusseau D (2015) Estimating spatial, temporal and individual variability in dolphin cumulative exposure to boat traffic using spatially explicit capture-recapture methods. Anim Conserv 18:20-31

*Potvin J, Goldbogen JA, Shadwick RE (2012) Metabolic expenditures of lunge feeding rorquals across scale: implications for the evolution of filter feeding and the limits to maximum body size. PLOS ONE 7:e44854

R Development Core Team (2008) R: a language and environment for statistical computing. R Foundation for Statistical Computing, Vienna

Richardson WJ, Greene CR, Malme CI, Thomson DH (1995) Marine mammals and noise. Academic Press, San Diego, CA

* Senigaglia V, Christiansen F, Bejder L, Gendron D and others (2016) Meta-analyses of whale-watching impact studies: comparisons of cetacean responses to disturbance. Mar Ecol Prog Ser 542:251-263

Southall BL, Bowles AE, Ellison WT, Finneran JJ and others (2007) Marine mammal noise exposure criteria: initial scientific recommendations. Aquat Mamm 33(Spec Issue):411-521

Stone GS, Katona SK, Mainwaring A, Allen JM, Corbett HD (1992) Respiration and surfacing rates of fin whales (Balaenoptera physalus) observed from a lighthouse tower. Rep Int Whaling Comm 42:739-745

Symons J, Pirotta E, Lusseau D (2014) Sex differences in risk perception in deep-diving bottlenose dolphins leads to decreased foraging efficiency when exposed to human disturbance. J Appl Ecol 51:1584-1592

Thompson D, Fedak MA (2001) How long should a dive last? A simple model of foraging decisions by breath-hold divers in a patchy environment. Anim Behav 61:287-296

Wedderburn RWM (1974) Quasi-likelihood functions, generalized linear models, and the Gauss-Newton method. Biometrika 72:31-38

Williams R, Lusseau D, Hammond PS (2006) Estimating relative energetic costs of human disturbance to killer whales (Orcinus orca). Biol Conserv 133:301-311

Zuur A, Ieno EN, Walker N, Saveliev AA, Smith GM (2009) Mixed effects models and extensions in ecology with R. Springer-Verlag, New York, NY

Submitted: July 18, 2016; Accepted: March 19, 2017

Proofs received from author(s): April 20, 2017 